\title{
Theoretical method to improve the placement of backfill behind barricades
}

\author{
Chris Lee \\ Golder Associates Ltd., Canada
}

SUMMARY: Mine backfill is typically placed in stopes with drawpoints or access drifts at the bottom of the stope. To contain the fluid backfill, barricades are required to prevent the flow of backfill out into the access drift. Typically barricades are constructed of muck or reinforced shotcrete; however, there are some disadvantages with typical barricade design and this paper examines some theoretical possibilities for a new barricade design that may improve safety, productivity, cycle time and the mines economics.

Keywords: Backfill, pastefill, barricades, bulkheads

\section{INTRODUCTION}

Paste backfilL is a fluid material that is placed in stopes after the extraction of ore. Typically, the ore is extracted from an access drift at the bottom of the stope and therefore, when placing paste backfill it is required to barricade the access drift in order to prevent backfill from flowing out into the drift. Backfill barricades are typically constructed out of reinforced shotcrete or simply waste rock and must retain the hydraulic head produced by the placement of the backfill.

A typical sequence of backfilling will include the installation of the barricade and filling of the stope up until a point just above the barricade. This initial backfill placement acts as a plug and serves as a monolithic barricade for future pours on top of the plug pour. The constructed barricade is therefore only required to support the initial plug pour and then the plug pour supports subsequent pours.

This barricading method has been used for many years with very little change in methodology or materials of construction. It serves its purpose well; however, there are a number of drawbacks associated with this typical method of barricade construction under certain situations as discussed below:

- For underhand stopes (i.e. stopes mined underneath a previously mined and backfill stope), it is frequently required to develop back through the previously placed backfill in order to establish a drilling horizon for the drilling of the next stope below:

- This results in additional waste production since the mined backfill will need to be hauled and disposed of,

- It also results in increased cycle time due to the requirement to develop through the backfill using drill/blast/ground support,

- Before a drift can be developed through the backfill the barricade will need to be removed which typically means blasting of the shotcrete barricade which takes some time and requires removal of the reinforced shotcrete waste materials,

- Drifting through backfill results in increased backfilling volume if the drill drift will later be filled with backfill; 
Table 1. Barricade related task durations - Note bolded items are related to areas where a new barricade method could reduce the backfill cycle time.

\begin{tabular}{lcc}
\hline Barricade construction & 3 & Days \\
\hline Plug pouring & 2 & Days \\
Plug curing & 7 & Days \\
Main body pouring & 5 & Days \\
Main body curing & 28 & Days \\
Removal of barricade & $\mathbf{1}$ & Days \\
Drifting through plug & $\mathbf{5}$ & Days \\
Additional pour time to fill drift void & $\mathbf{0 . 5}$ & Days \\
Total & 51.5 & Days \\
\hline
\end{tabular}

- A muck or shotcrete barricade requires a period of construction for the barricade which also delays cycle time. Typically, this construction period is 1-3 days depending on the type of barricade used;

- Conventional barricades require a delay period to cure the plug pour before the main body pour can commence. Typically, this curing period is 7 days or more; however, if there is a demand for a quick turnaround on cycle time, then it is possible to reduce the curing time by adding more cement which incurs additional binder costs.

The total, barricade related, task durations are listed below in Table 1. It should be noted that none of these tasks are typically performed concurrently and therefore any reduction in any one of these task durations will result in a reduction of overall cycle time. Although there is an option to perform some of these tasks concurrently there is additional risk associated with this and generally it is avoided.

Although there are parts of this backfilling cycle that are not improved by a change in barricading method, there are some portions of the cycle that can be improved such as the barricade construction time, plug curing time, removal of barricade, drifting through plug and additional time to fill drift void. The total time in the backfill cycle that is potentially available for improvement is significant ( 16.5 days of potential savings out of the 51.5 days total backfilling cycle time).

In addition to cycle time improvements, there are significant costs associated with these identified tasks. Particularly with the task of removing the shotcrete barricade and developing through the plug. These tasks are where the opportunity for improvement in the backfilling economics is most prevalent.

\section{ALTERNATIVE BARRICADING METHOD CONCEPT DEVELOPMENT}

In developing the alternative barricading concepts, the first step was to identify what properties the new barricade would have and relate those properties to the opportunities for improvement identified above. This relationship between barricade properties and opportunities is summarized below:

- Shorten the barricade construction period - reduce cycle time;

- Robust enough to support full weight of main body fill to eliminate the 7 days waiting period for plug curing - reduce cycle time;

- Provides a void at the access drift level so that no development in fill is required - reduce cycle time and reduce development and refilling costs;

- Reduce exposure of personnel to work near the mouth of the stope - Automate barricade construction to minimize personnel involved and keep their location far from the stope;

- Reduce the potential for barricade failure - Change the barricade design concept so that the mechanisms for failure are reduced or that additional redundancy is provided. 
The list of opportunities and desirable outcomes above was used to direct the concept development of what a preferred barricade design would look like. Since the main drivers for improvement in cycle time and costs revolves around the ability to construct the barricade more quickly, eliminate plug curing time and eliminate the development through the backfill, the ideal barricade method will incorporate the ability to create a void in the stope that prevents a certain portion of the stope from being filled. Essentially the barricade should be a type of tunnel form that prevents the backfill from flowing into the area of the plug pour that will be required to be opened up in the future.

Options were developed and evaluated and are discussed below.

\subsection{Waste filled tunnel form}

This concept can be seen in Figures 1 through 12 below. The concept includes a type of remotely installed formwork that allows waste to be placed in the desired geometry to prevent the inflow of paste into the desired void. Essentially the formwork retains the waste rock in the desired geometry and the waste rock supports the load of the paste once the stope is filled.

The concept includes a set of sprung steel arches that provide containment for muck placed inside the form. Between the arches is a heavy duty reinforced rubber fabric (similar to flexible vent ducting). The steel arches provide the principal support to take the majority of the load and the rubber provides the secondary support and containment to prevent rocks from exiting the tunnel form.

With the tunnel form installed and waste rock placed in the tunnel form, the stope can be filled with cemented paste backfill or any other fill type without stopping to wait for the plug to cure since the waste rock will support the full load of the main pour. Once the backfill has cured, the waste can be extracted much more easily than drilling and blasting through fill.

Although simple in concept there are a number of challenges with the waste filled tunnel form concept as follows:

- Extending the tunnel form to the end of the stope will require mechanised equipment to move under unsupported ground. It is proposed that the best way to move the tunnel form assembly is by:

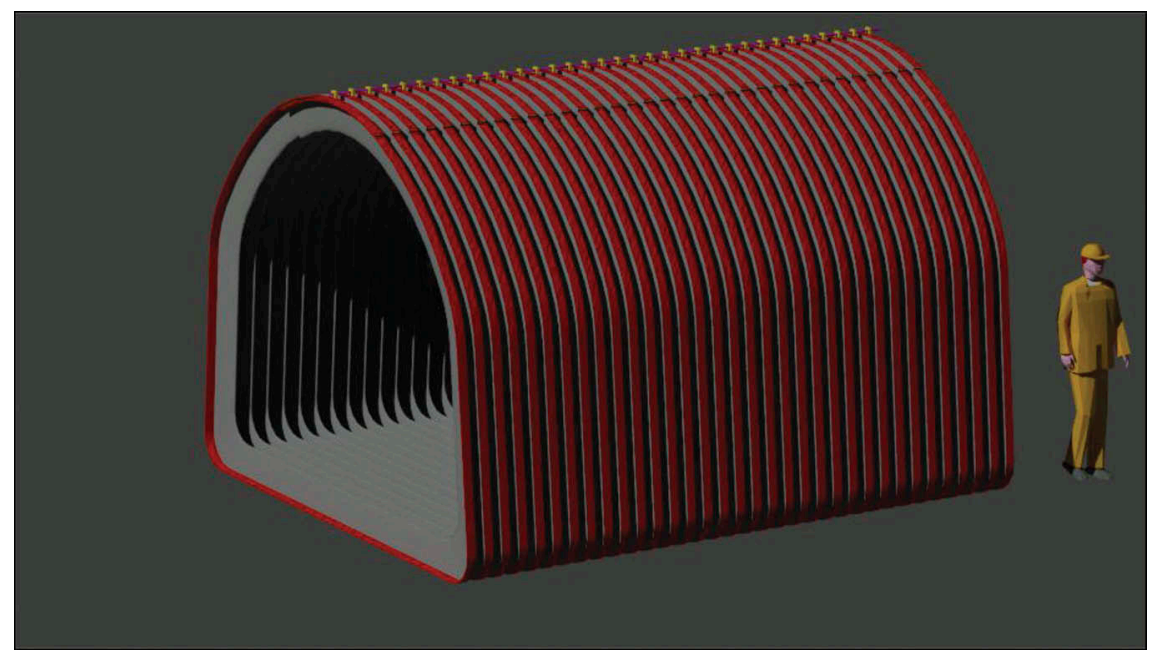

Figure 1. Tunnel form linkage and pin arrangement. 


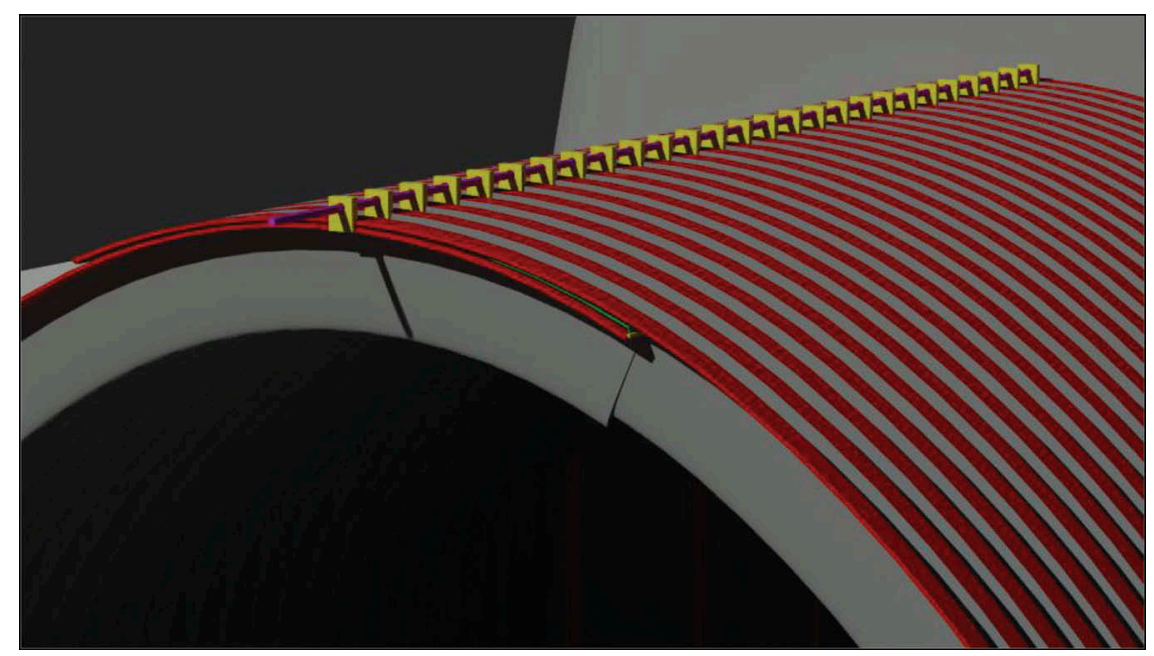

Figure 2. Tunnel form in its packed position. The rod through the tabs keeps the sprung steel frame from expanding to its full diameter and the plastic liner is folded into the collapsed frame.

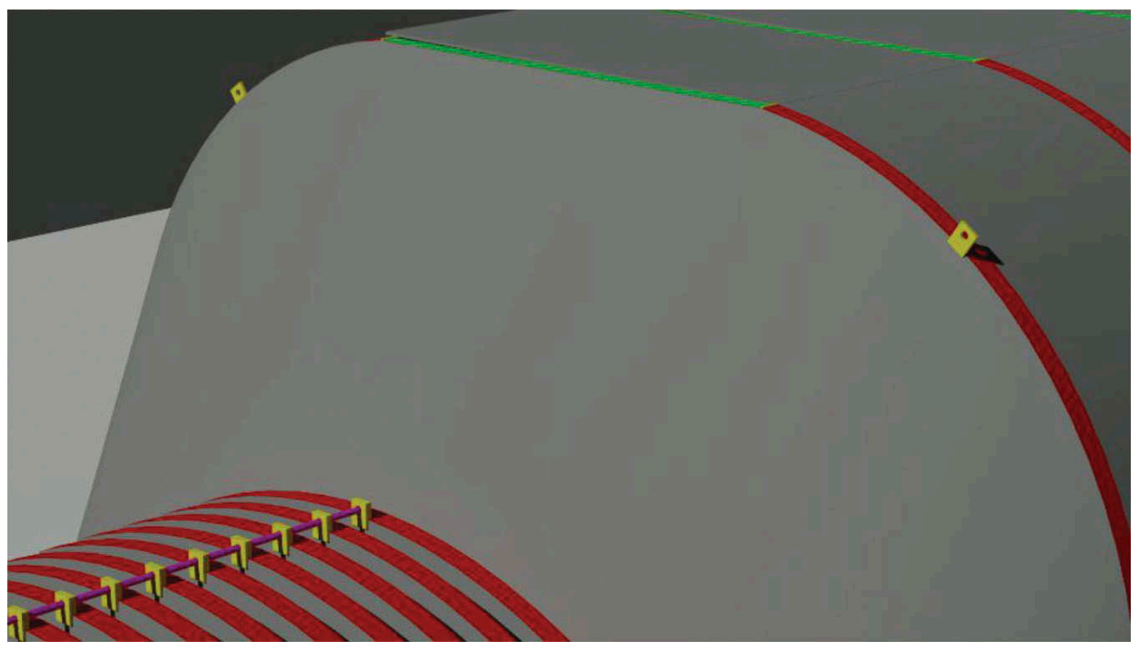

Figure 3. As the tunnel forms are pulled into the stope the tabs are pulled off the rod and the sprung steel snaps out to its full diameter, restrained by a cable that holds the ends of the steel frame together.

- The tunnel form assembly will be connected to a monolithic end weight that will be installed at the far end of the stope (away from the drawpoint). That monolith will be lifted by a remote scoop and the scoop will deposit it at the far end of the stope. Once the scoop retreats to the mouth of the drawpoint it will connect its bucket to the tunnel form pulley and then pull the tunnel form to the monolith by driving backwards out of the drawpoint. Alternatively, the tunnel form pulley assembly could have a mobile tugger that is used to pull the tunnel forms to the monolith;

- The tunnel form profile will ideally be the same profile as the access drift. Of course, this will mean that it is difficult to move the tunnel forms around the access drift or into the mine itself if they are too large. While it is possible that the tunnel forms could be made to 


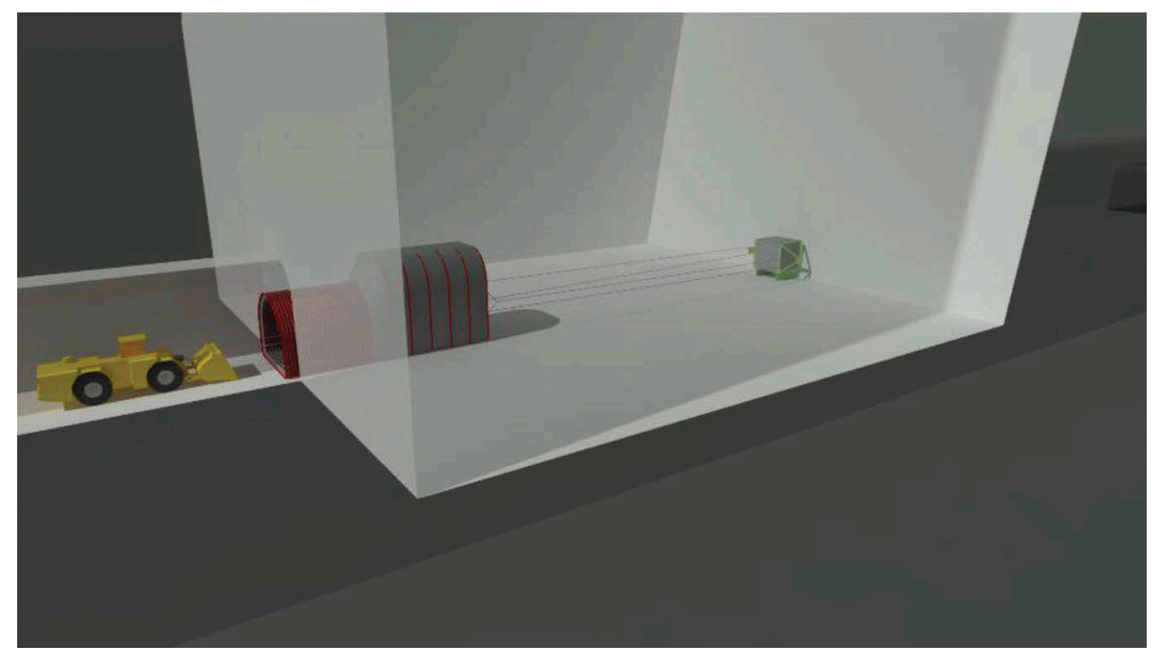

Figure 4. A monolith is installed at the far end of the stope by the scoop in remote mode. The tunnel form is pulled to the monolith by pulley cables. As the tunnel form is pulled into the stope the sprung steel arches snap out to a larger dimension as the rod tabs on each arch are pulled off the rod and the arch snaps out to a dimension that is limited only by the cable tie between the ends of the arch.

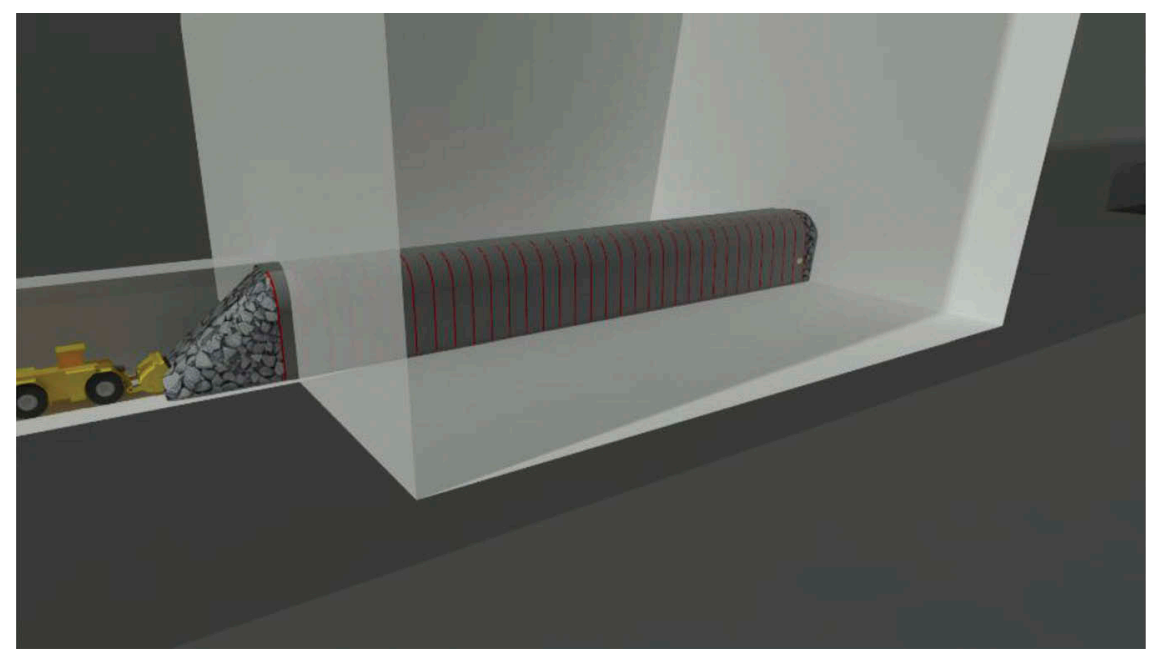

Figure 5. Waste rock is placed in the tunnel form by remote scoop. The scoop will likely not fill the rock perfectly tight to the top of the form but the idea is to fill the majority of the tunnel form with rock.

be slightly smaller than the mine access drifts, it is likely that this will reduce the effectiveness of the drill drift and is undesirable. To address this the sprung steel tunnel form, members will be packed into a smaller cross section with a linkage and rod arrangement so that as the pins are extracted, the sprung steel members will snap outwards to the limits of the linkage (shown in Figure 1). The tunnel form assembly will be mounted on a skid with the rubber folded to the inside and as the tunnel form is extended to a point beyond the mouth 


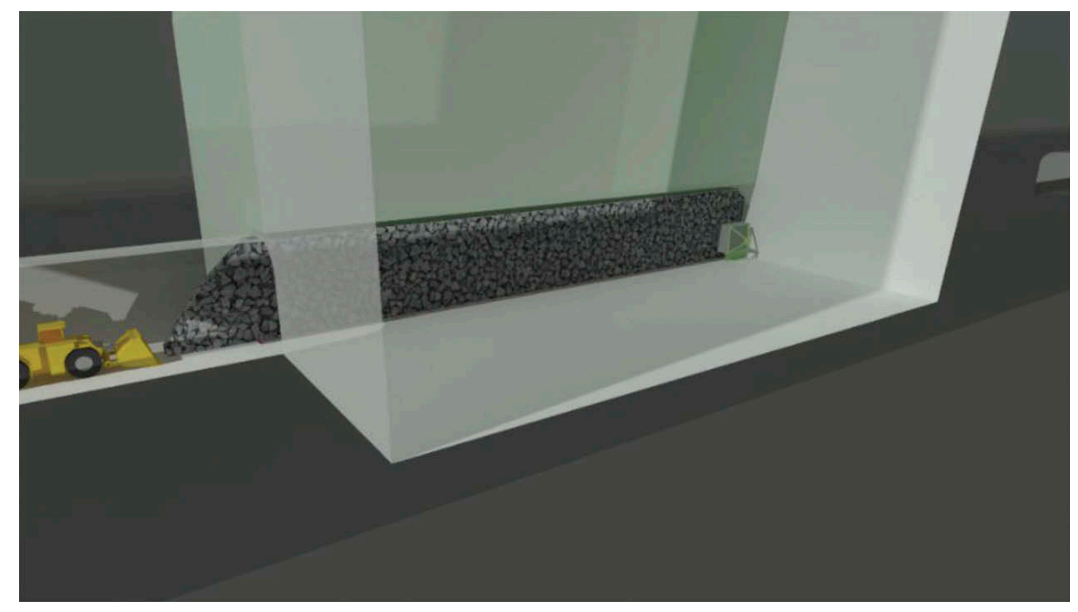

Figure 6. Paste poured to top of stope - With waste rock filling the tunnel form it can withstand the full pressure of the filled stope. The key is to seal the drawpoint area to ensure that fill can't short circuit from the stope through the mouth of the tunnel form.

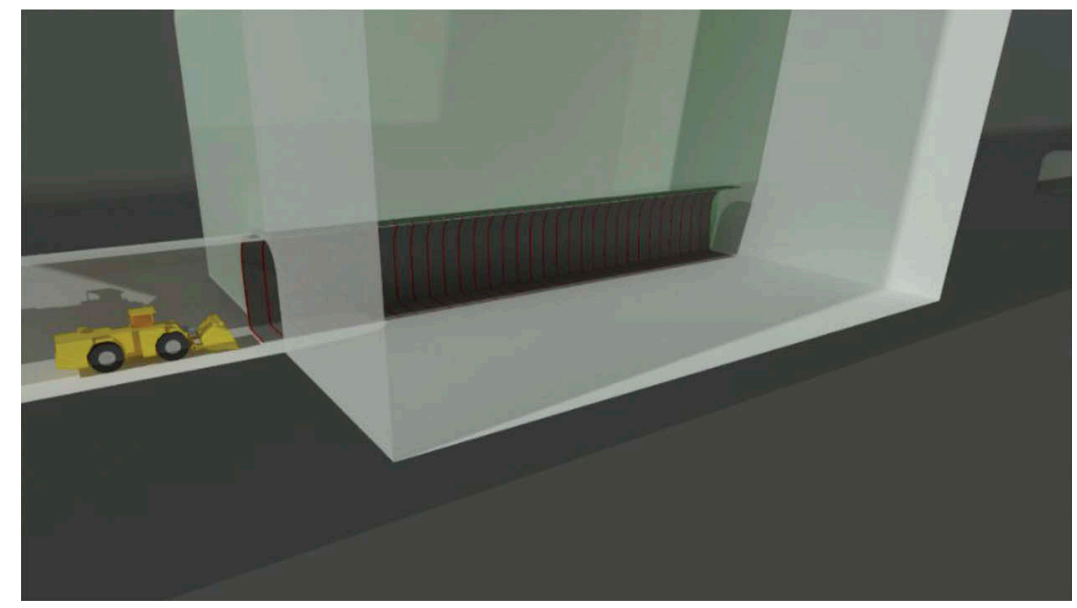

Figure 7. Waste rock and monolith removed from tunnel form by remote scoop.

of the access drift, the rod will be pulled out of their holes and the sprung steel will snap out to the full dimensions of the form.

- Filling the tunnel form will be accomplished by using a remote scoop which will bring waste rock or ore to the tunnel form and place it within the extent of the form (from the monolith to a point several meters outside of the stope). Although it is considered likely that the waste rock and tunnel form rubber alone will seal the stope it may be required to shotcrete the interface between the tunnel form and the drawpoint back in order to ensure a tight seal.

- Once the tunnel form is full the stope can be filled with backfill and allowed to cure.

- After curing, the waste rock can be mucked out by the scoop and ground support put in place. 


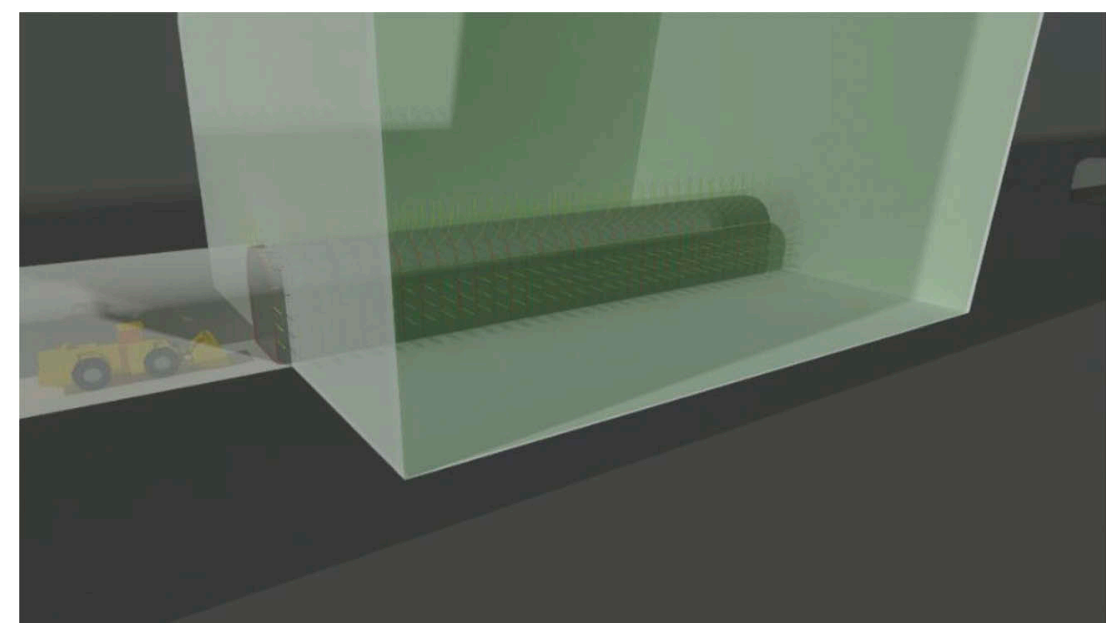

Figure 8. Ground support installed if required. Note that it is possible that ground support could be incorporated into the tunnel form design so that it is embedded in the paste during pouring.

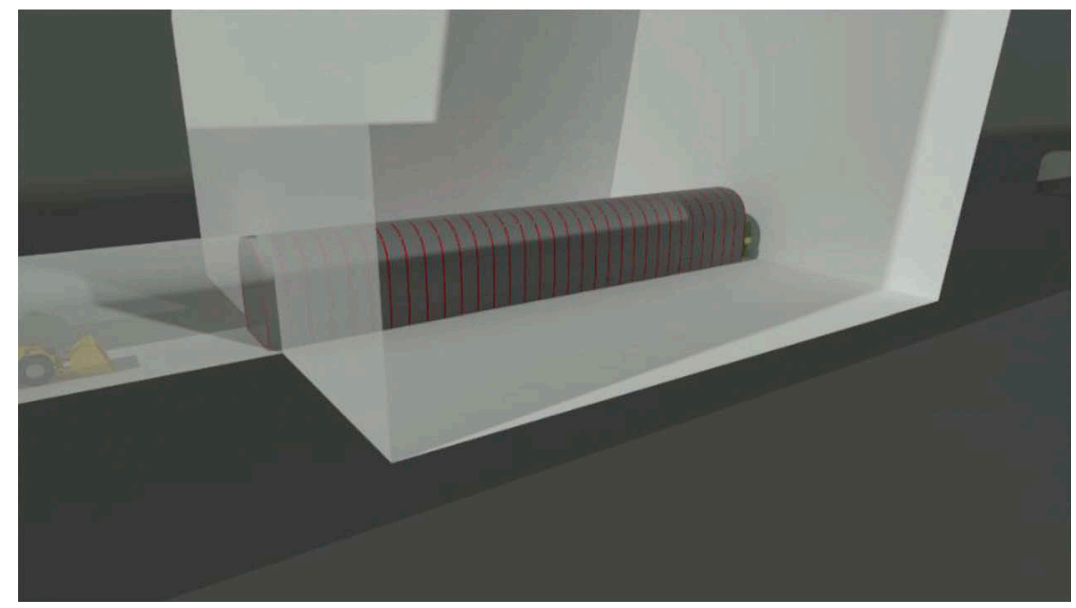

Figure 9. Void form installed.

\subsection{Empty tunnel form (void form)}

As an alternative to the waste rock tunnel form, it is possible that the form be used without waste rock and use the structural strength of the sprung steel members to prevent fill from entering the form. The installation method for placing the tunnel form would be exactly the same as with the waste rock filled tunnel form; however, there are several key differences in the properties of this type of barricade:

- Since the form would not be filled with waste rock, it would have to be substantially stronger than the waste rock tunnel form in order to support the collapse pressure (rather than hoop stress pressure) due to the weight of the main body fill above. It is likely that this method would be more practical if the pour height was limited to a plug pour height (typically $7 \mathrm{~m}$ ); 


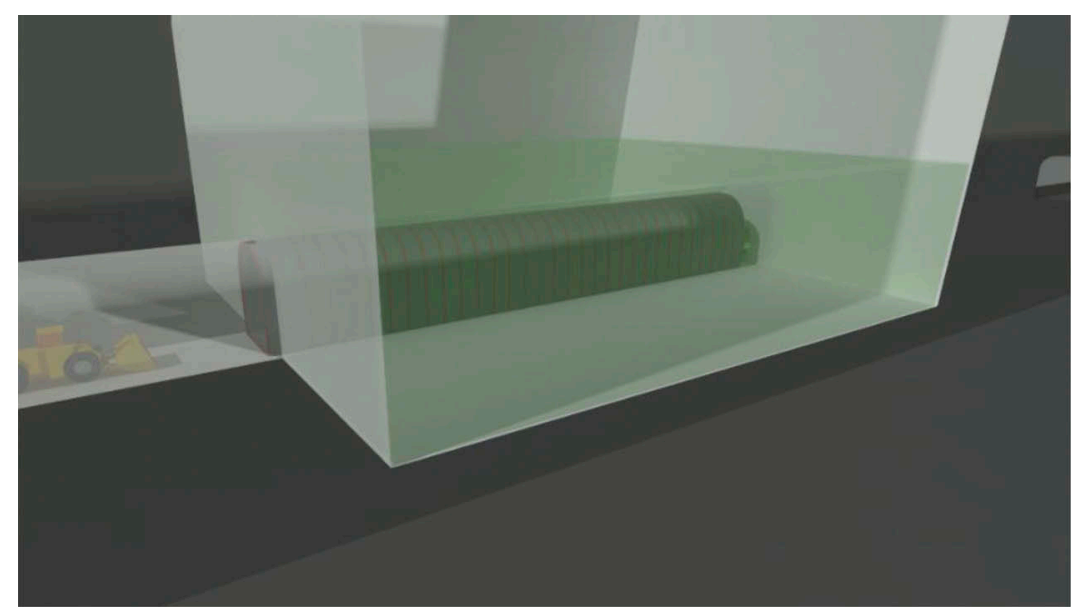

Figure 10. Paste plug poured to $8 \mathrm{~m}$ above floor ( $2 \mathrm{~m}$ above tunnel form).

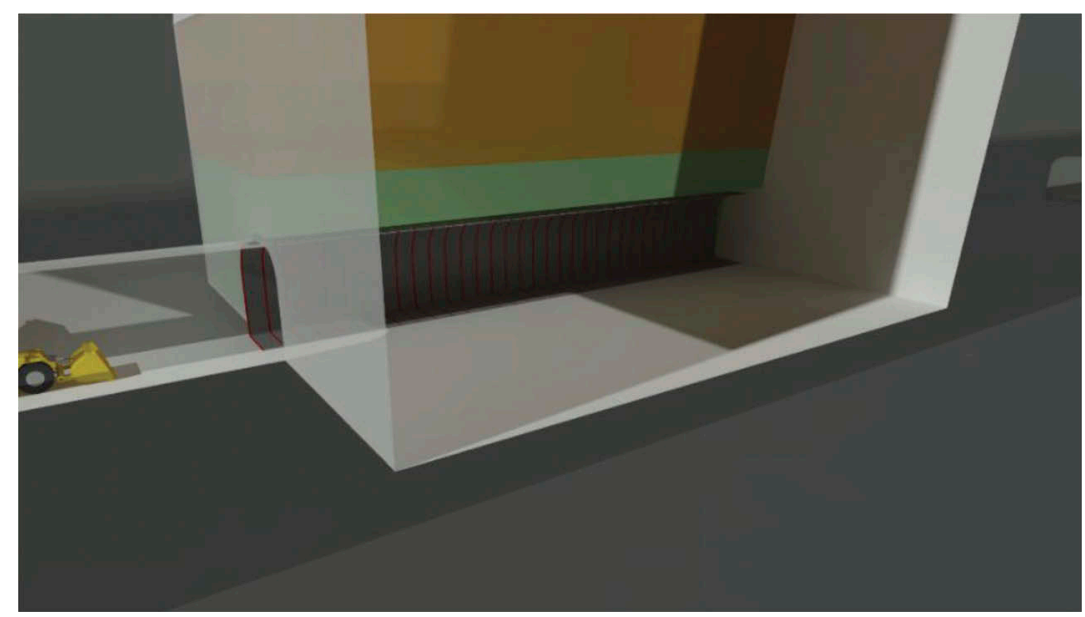

Figure 11. Main body pour.

however, this compromise would limit the effectiveness of the tunnel form since one of the key advantages of the tunnel form is the potential to eliminate the 7 days curing period for the plug pour.

- With waste rock in the form it does not really matter if the tunnel form has rips and tears in it or whether there are leakage paths into the form from the exterior of the stope. All those leakage paths can fill the voids that remain inside of the waste filled tunnel form without compromising the overall concept. With the void tunnel form any major leakage path will prevent the tunnel form from working and filling would need to stop while the leaking area was repaired. Repairs to a leaking form when no personnel access is allowed would be difficult and in the end, the recovery plan may be the placement of waste rock and the use of the void form in the exact same way as the waste rock filled form.

- Because the void form is empty and the surrounding fill will have an SG of approximately 1.7 to 2.0 , there is the potential that unless anchored to the floor of the stope, the void form 


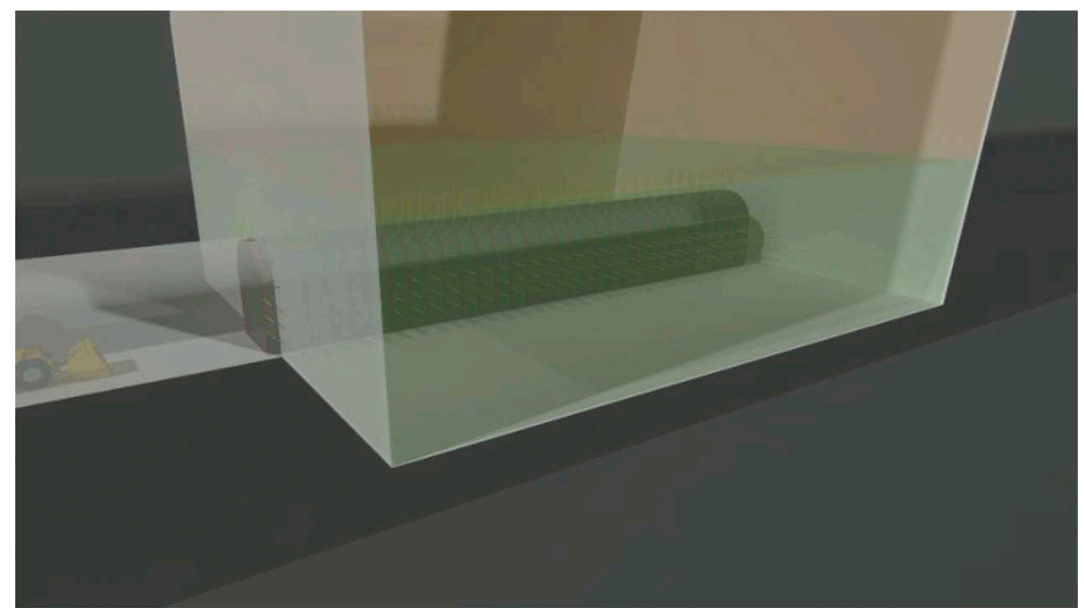

Figure 12. Ground support.

will float on the surface of the placed fill and may have an irregular floor or even a major heave in the floor in between the fixed points at the monolith and the stope drawpoint. Although this can be rectified by the placement of weights on the tunnel forms by some remote method, it is another step that contributes to the complication of this option.

- The major advantage of the void form is that there is no requirement to fill the form with waste rock or remove that waste rock. Although this is not a major cycle time component in comparison with waiting for the plug to cure or developing through fill, it would likely be at least 1 or 2 days of scoop time in order to fill with waste rock and then remove the waste rock.

\subsection{Other considerations}

Building from the basic concepts described above, there are other opportunities that may be achievable and beneficial for the mine to consider:

- Elimination of ground support step(s) - it is possible that with the design of a tunnel form that integrates elements of ground support into the form itself, that some, or all, of the post filling ground support could be eliminated. For example, it is possible that the sprung steel main form members could have both mesh and anchor bolts attached as part of the form structure. As the forms are pulled into the stope the mesh and bolts could swing into place (i.e. anchor bolts pop up to be perpendicular to the form face) so that when the backfill is placed it becomes integrated with the backfill and essentially provides reinforcement for the backfill. The downside is that this would make the tunnel form more complicated which will result in more potential for operational difficulties. The elimination of ground support steps could be complete (i.e. no bolts, shotcrete or screen since those would be replaced by the tunnel form structure) or it could be partial (maybe only bolts will be part of the tunnel form structure and shotcrete and screen will still be applied). It is also possible that ground support could be improved with the tunnel forms since the bolts and screen are embedded in the backfill. With embedded bolts rather than drilled and anchored bolts there are design options such as $\mathbf{J}$ hooks for bolts that could be considered to provide greater pullout resistance or reduce the bolt length.

- Re-usability of the barricade - It is possible that instead of the tunnel form being a consumable that it could be made to be re-usable. The potential to use a more robust, all steel tunnel form that could be put into place and then retracted could reduce the cost of tunnel form consumables. The method of extracting the form is the major hurdle to this 
concept since it would likely be a very heavy steel structure that would be difficult to move around with limited access, cranage and adhesion to the backfill. In addition, it is likely that the steel forms would be damaged by the placement of waste rock and the time to repair the forms would likely be significant. It does, however remain a possibility.

\section{CONCLUSION}

The potential for using tunnel forms to improve barricading practice for underhand mining methods appears to be quite possible. Based on an initial review of the tunnel forming options above, it is likely that the use of waste rock filled tunnel forms will be a more viable alternative than void forms.

To advance this concept further to the piloting stage it would require a relatively small investment to perform the design and fabricate prototype tunnel forms. Due to the low cost of trialling this concept and the potential high payback for cycle time constrained underhand mining operations, this is a concept that mine operators should consider investigating in the near future. 